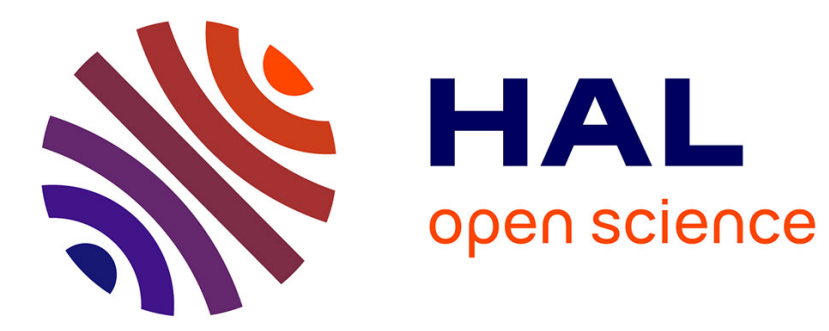

\title{
Dislocation mechanisms of creep in $\mathrm{Ni3Al}$
}

\author{
T. Rong, I. Jones, R. Smallman
}

\section{To cite this version:}

T. Rong, I. Jones, R. Smallman. Dislocation mechanisms of creep in Ni3Al. Journal de Physique IV Proceedings, 1993, 03 (C7), pp.C7-457-C7-460. 10.1051/jp4:1993772 . jpa-00252192

\section{HAL Id: jpa-00252192 https://hal.science/jpa-00252192}

Submitted on 1 Jan 1993

HAL is a multi-disciplinary open access archive for the deposit and dissemination of scientific research documents, whether they are published or not. The documents may come from teaching and research institutions in France or abroad, or from public or private research centers.
L'archive ouverte pluridisciplinaire HAL, est destinée au dépôt et à la diffusion de documents scientifiques de niveau recherche, publiés ou non, émanant des établissements d'enseignement et de recherche français ou étrangers, des laboratoires publics ou privés. 


\title{
Dislocation mechanisms of creep in $\mathrm{Ni}_{3} \mathrm{Al}$
}

\author{
T.S. RONG ${ }^{*}$, I.P. JONES ${ }^{*, * *}$ and R.E. SMALLMAN* \\ * School of Metallurgy and Materials \\ ** IRC in Materials for High Performance Applications, The University of Birmingham, Bimingham B15 \\ 2TT, England
}

\begin{abstract}
The compressive creep deformation microstructure of polycrystalline $\mathrm{Ni}$ Al has been observed by transmission electron microscopy $($ TEM). $<11(1)\{111\}$ and $<110>\{11(0\}$ slip systems have been identified in primary creep. Dissociation of edge superpartial pairs perpendicular to the slip plane (both $\{111\}$ and $\{110\})$ is common in crept specimens. The formation of this superdislocation configuration is thought to limit the extent of primary creep defomation.
\end{abstract}

\section{Introduction}

The creep behaviour of Ni3Al at intermediate temperatures does not display the three typical stages characterised as primary, steady-state and tertiary. Instead, after primary creep, the rate continually increases with creep strain $[1], \mid 2\},\{3\}$. A model of the processes controlling the intermediate temperature creep behaviour of $\mathrm{Ni}_{3} \mathrm{Al}$ has been sliggested by Hemker et al [3]. In primary creep, the octahedral glide of superpartial dislocation pairs, which have a planar dissociation, results in a comparatively high initial creep deformation rate. Subsequently, thermally activated cross-slip of the screw segments onto a cube plane to form K-W locks immobilizes the superdislocations. This leads to exhaustion of octahedral glide and reduces the strain rate. After the screw segments are locked, the edge segments continue to expand on the octahedral plane. As first proposed by Mills et al.|4| the dislocation structure associated with an expanded loop is a series of K-W locks connected by edge segments on the octahedral plane. Each K-W lock has the capacity to be a Frank-Read dislocition source on the cube plane. Given sufficient time and temperature, the cross-slipped screw segments are able to bow out and glide on the cube plane. The production and multiplication of dislocations on the cube plane lead to an increasing creep rate, i.e. inverse creep. In the present investigation, superdislocation dissociation, especially of the edge segments, is studied by means of transmission electron microscopy (TEM) in polycrystalline $\mathrm{Ni}_{3} \mathrm{Al}$ crept at an intermediate temperature. An attempt is made to understand the superdislocation dissociation and its influence on the creep behaviour.

\section{Experimental Procedure}

A polycrystalline $\mathrm{Ni}_{3} \mathrm{Al}$ ingot was prepared for the present investigation. The ingot was homogenized at $1050^{\circ} \mathrm{C}$ for three days in vacuum. Specimens with dimensions $4.5 \mathrm{~mm} \times 4.5 \mathrm{~mm} \times 9.0 \mathrm{~mm}$ were cut by spark machine. Creep tests were carried out on an ESH $200 \mathrm{kN}$ material testing machine at $580^{\circ} \mathrm{C}$ in air. After the creep tests, the specimens were guenched into an ice bath. TEM specimens were made with electrochemical polishing using a twin jet polisher and a solution of $55 \%$ ethanol, 32\% butoxyethanol, $8 \%$ perchloric acid and $5 \%$ glycerol at $\sim 10^{\circ} \mathrm{C}$. TEM observations were carried out with a JEOL 40)()-FX microscope.

\section{Experimental results and discussion}

Creep of polycrystalline $\mathrm{Ni}_{3} \mathrm{Al}$ exhibits a normal primary creep region and then an inverse creep region as shown in Fig. 1, which agrees with the results of previous investigations [1],|2],|3|. TEM observation indicated that in primary creep dislocations with Burgers vector $<110\rangle$ were the major defect. Some stacking faults could be seen, especially near the grain boundaries. Distribution of dislocations was inhomogeneous, depending upon crystal orientation. Fig.2 shows that dislocations are predominantly of screw character. By specimen tilting, slip systems and superdislocation dissociations were identified. Fig.3 shows a set of weak-beam inages of an elongated dislocation loop with $b=[\overline{1}(01]$ and a corresponding 
configuration. It suggests that the loop lies on (111). The edge segment of dislocation dissociates on (010) to form a Kear-Wilsdorf lock and its screw segment dissociates on (T01), the plane perpendicular to the slip plane. Another tilting observation is shown in Fig. 4 where a different configuration from $\{111\}$, a dislocation loop on $\{110\}$ is suggested. Again, the screw dissociates on (010) and pure edge on (101), perpendicular to the slip plane. Caron et al. [5] first observed $\left\langle 110>\{110\}\right.$ slip in $\mathrm{Ni}_{3} \mathrm{Al}$ single crystals crept along $\sim[001]$ at $760^{\circ} \mathrm{C}$. They reported that there is no preferential expanding orientation for $\{110\}$ slip. They, therefore, declared that expansion of the dislocations was controlled by APB dragging. However, in the present investigation, the dislocation loop is elongated along the screw orientation (the direction of the Burgers vector). Thus, the shape of the dislocation loop may suggest slip rather than APB dragging. In addition, when a dislocation loop is small, a planar dissociation on the slip plane $\{110\}$ may be observed as examplified by Fig.5.

The evolution of superdislocation dissociation could, therefore, take place in the way sketched in Fig.6. In the early stages, the superdislocation loops on $\{111\}$ or $\{110\}$ planes dissociate in their slip planes (a planar dissociation). Both edge and screw segments have a relatively high mobility. Because of the anisotropy in APB energy (a minimum on $\{001\}$ [6]), and because of the torque between the two screw superpartials (which torque is zero on $\{001\}$ [7]), the screw segments cross slip to $\{001\}$ first to form the $\mathrm{K}-\mathrm{W}$ locks because cross-slip is easier than the climb dissociation of the edge segments at this temperature. Thus, the screw segments become sessile. Meanwhile, edge segments still maintain a planar dissociation and keep travelling on the slip plane. This is the case generally considered in the specimens during constant strain rate deformation. Thus, the superdislocation loop will elongate along the Burgers vector direction. If given enough time and temperature, climb dissociation occurs in the edge segments. Based on this evolutionary process of the dissociation of superdislocation loops during creep deformation, the explanation for the decrease of creep rate with increasing creep strain is that, in the initial stage, whole superdislocation loops dissociate on their slip planes, $\{111\}$ or $\{110\}$. This planar dissociation leads to a high creep rate at the beginning of primary creep. Since cross-slip of the screw segment is relatively easier than climb dissociation of the edge segment at intermediate temperatures, the $\mathrm{K}-\mathrm{W}$ configuration is produced first. Thus, the creep rate decreases. However, the shape of the superdislocation loop implies that it is the movement of the edge segment that contributes appreciably to the creep deformation. Thus, it is reasonable to think that at this stage the creep rate does not reduce too much. This could correspond to the initial portion of the creep curve with a slow decrease of creep rate (Fig. 1). Since the configuration for the two edge superpartials connected by a strip of APB on their slip plane is metastable, as first pointed out by Flinn [6], given enough time and temperature, climb dissociation occurs. This dissociation of the edge segment immobilizes the dislocation. A rapid decrease of creep rate takes place. This is observed in a later stage of primary creep. In the previous work [3], the formation of K-W locks on screw segments was thought to be the chief reason for the decrease of creep rate in primary creep. However, the contribution of the screw segments to creep deformation is much less than that of the edge segments. Therefore, it is more likely that the mobility of the edge segments, rather than the screw segments, controls the creep rate in primary creep.

\section{Conclusions}

At intermediate temperatures, $<110>\{111\}$ and $<110>\{110\}$ slip systems are both active in primary creep. In this creep regime, the creep strain is mainly due to the movement of edge dislocations on their slip plane. Meanwhile, dissociation of the edge segments perpendicular to the slip plane $(\{111\}$ or $\{110\})$ is a common dislocation configuration in the crept specimens. The formation of this configuration limits the extent of primary creep deformation and results in the decrease of creep rate.

\section{Acknowledgments}

The authors are grateful to Dr. A.H.W. Ngan for many helpful discussions, to Dr. P. Bowen for the use of mechanical test equipment and to Professor J.F. Knott for the provision of laboratory facilities. T.R. would like to acknowledge the School of Metallurgy \& Materials, University of Birmingham, for financial support.

\section{References}

1. Anton, D.L., Pearson, D.D., and Snow, D.B., High-temperature Ordered Intermetallic Alloys MRS, 81 (1987) 287.

2. Schneibel, J.H., and Horton, J.A., J. Mater. Res. 3 (1988) 4.

3. Hemker, K.J., Mills, M.J., and Nix, W.D., Acta Metall., 39 (1991) 1901.

4. Mills, M.J., Baluc, N., and Karnthaler, H.P., High-Temperature Ordered Intermetallic Alloys, MRS, 133 (1989) 203.

5. Caron, P., Khan, T., and Veyssiere, P., Phil. Mag. A, 60 (1989) 267.

6. Flinn, P.A., Trans. AIME, 218 (1960) 145.

7. Yoo, M.H., Acta Metall., 35 (1987) 1559. 


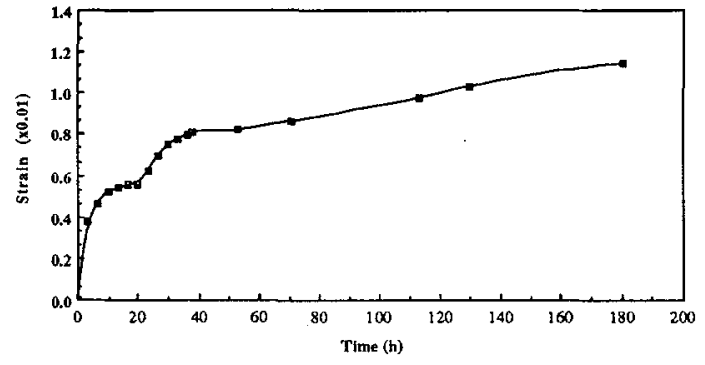

Fig.1 Uniaxial compressive creep curve of $\mathrm{Ni} 3 \mathrm{Al}$ at $580^{\circ} \mathrm{C}$ and $400 \mathrm{MPa}$.
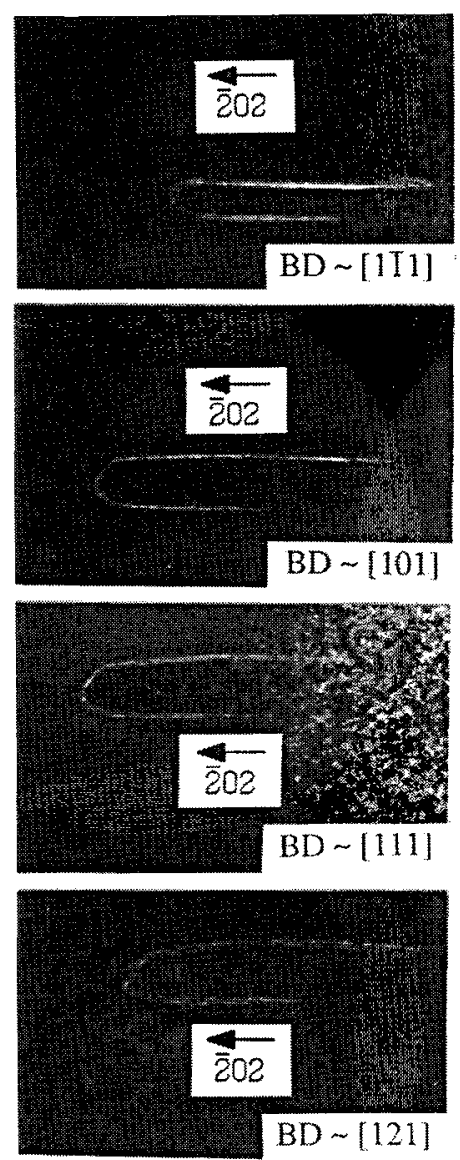

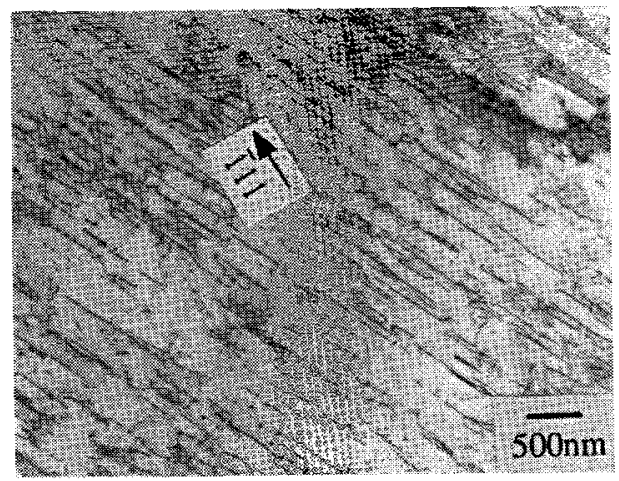

Fig.2 A bright-field image shows long and straight screw dislocations in the specimen crept for 10 hours.

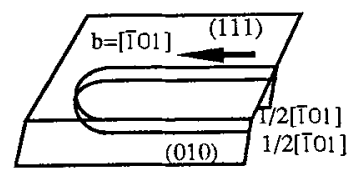

A schematic diagram corresponding to the configuration
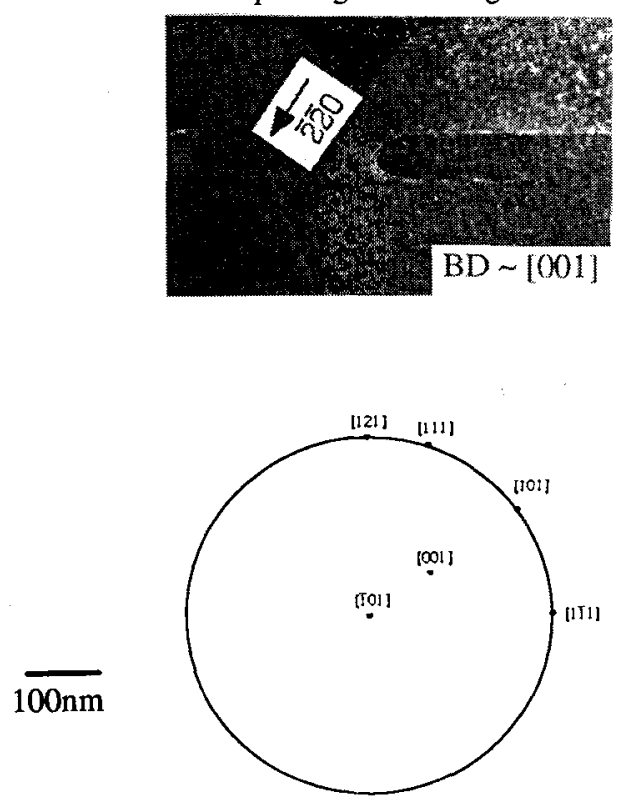

Tilting Path

Fig. 3 A weak-beam tilting experiment indicates and reveals the planes of the loop and the dissociation for $<110>\{111\}$ slip in the specimen crept for 10 hours. 

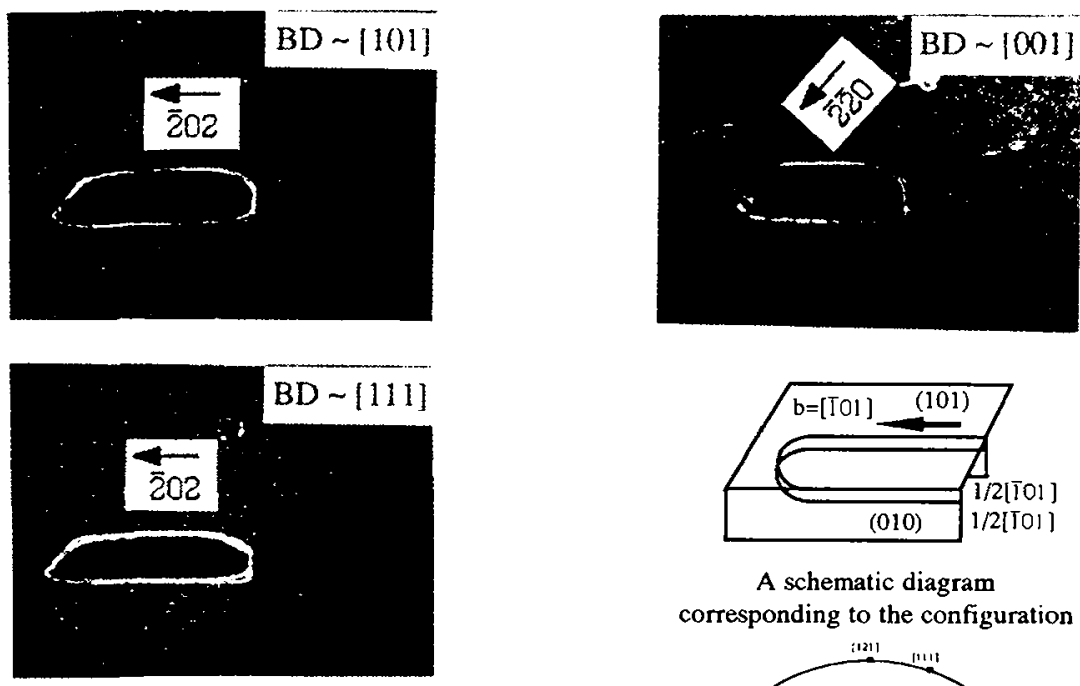

A schematic diagram corresponding to the configuration
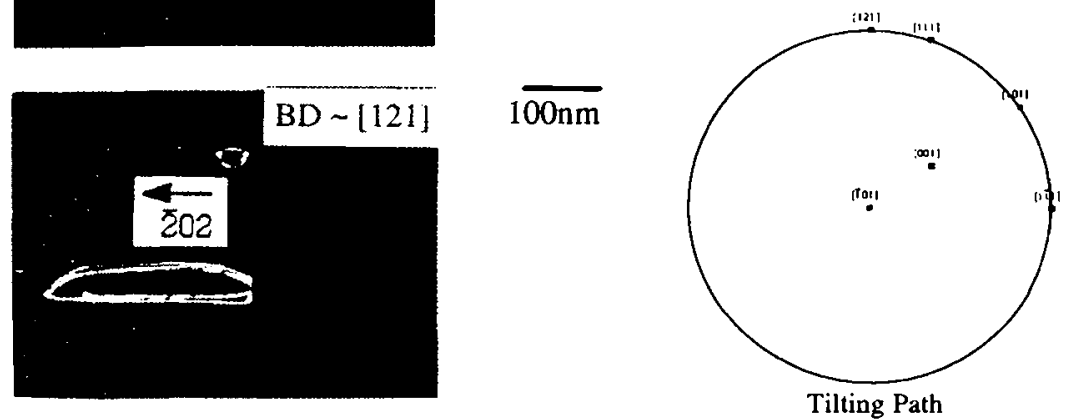

Fig. 4 A weak-beam tilting experiment indicates and reveals the planes of the loop and the dissociation for $<110>\{110\}$ slip in the specimen crept for 10 hours.

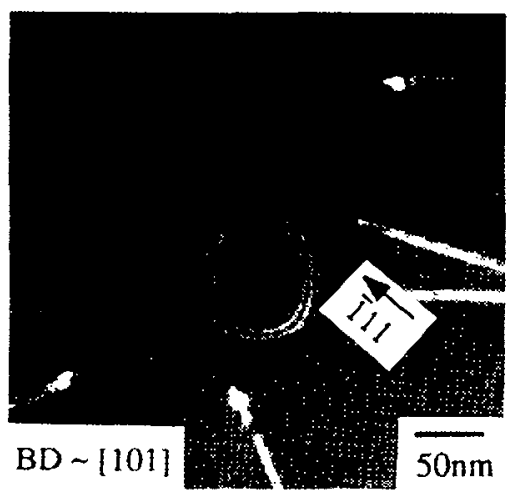

Fig. 5 Planar dissociation of a small superdislocation loop on $\{110\}$.

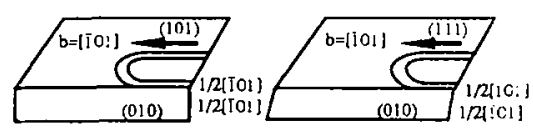

a)

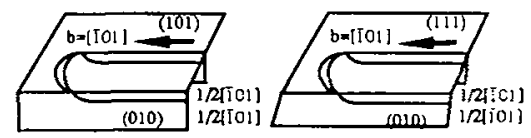

b)

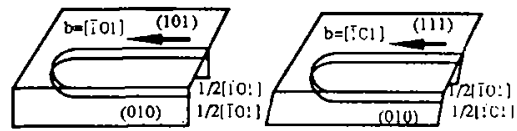

$<110>\{110\}$ slip $\quad$ s $110>\{111\}$ slip

Fig. 6 Evolution of the superdislocation for $<110>\{110\}$ and $<110>\{111\}$ slip. 